\title{
Effects of Palm Olein-Olive Oil Blends on Fat Deposition in Diet-Induced Obese Mice
}

\author{
Soek Sin Teh ${ }^{1, *}$, Siau Hui Mah ${ }^{2}$, Shiou Wah Gouk ${ }^{3}$, Phooi Tee Voon ${ }^{3}$, Augustine Soon Hock Ong ${ }^{4}$, \\ Yuen May Choo ${ }^{5}$ \\ ${ }^{1}$ Energy and Environment Unit, Engineering and Processing Division, Malaysian Palm Oil Board, Kajang, Selangor, Malaysia \\ ${ }^{2}$ School of Biosciences, Taylor's University, Lakeside Campus, Subang Jaya, Selangor, Malaysia \\ ${ }^{3}$ Product Development and Advisory Services Division, Malaysian Palm Oil Board, Kajang, Selangor, Malaysia \\ ${ }^{4}$ Malaysian Oil Scientists' and Technologists' Association (MOSTA), Petaling Jaya, Selangor \\ ${ }^{5}$ Malaysian Invention and Design Society (MINDS), Petaling Jaya, Selangor \\ *Corresponding author: ssteh@mpob.gov.my
}

\begin{abstract}
Current knowledge on the partial replacement of palm olein with olive oil on fat deposition is inadequate, thus leading to our interest to unveil the effects of palm olein on fat deposition by using mouse model. Our findings revealed that the normalized subcutaneous adipose tissues weight, liver weight and body weight gain of mice fed with either palm olein or the blends were remarkably lower than the mice fed with olive oil. The weight of subcutaneous adipose tissues of mice fed with palm olein and blend (PO:OO=50:50) were significantly lower than the mice fed with olive oil. In addition, body weight of the mice in palm olein group were significantly lower than those fed with olive oil group. The results implied that the mice fed with palm olein and palm olein-olive oil blends are less fattening than those fed with olive oil.
\end{abstract}

Keywords: Palm olein-olive oil blends, regiospecific, saturated fatty acids, fat deposition in mice

Cite This Article: Soek Sin Teh, Siau Hui Mah, Shiou Wah Gouk, Phooi Tee Voon, Augustine Soon Hock Ong, and Yuen May Choo, "Effects of Palm Olein-Olive Oil Blends on Fat Deposition in Diet-Induced Obese Mice." Journal of Food and Nutrition Research, vol. 6, no. 1 (2018): 39-48. doi: 10.12691/jfnr-6-1-7.

\section{Introduction}

The nutritional properties and versatility of palm oil have ranked it as a superb vegetable oil in food industry. It has a myriad of food uses including cooking oils, margarines, shortenings, cocoa butter equivalents, etc. Palm oil has excellent stability and dietary benefits due to the presence of natural source of tocopherols, tocotrienols and carotenoids. The presence of natural vitamin $\mathrm{E}$ in palm oil ensures a longer shelf-life for palm-based food products. Furthermore, tocotrienols have been reported to exert anti-oxidant and natural inhibitors of cholesterol synthesis [1]. Recent human and animal feeding experiments showed that palm oil does not elevate serum cholesterol and LDL-cholesterol levels, in fact, it decreases these values compared to other sources of saturated fats of animal and vegetable origins. The cholesterolaemic effect of palm oil is intermediate between the more unsaturated oils and the traditional sources of saturated fats. The effects of palm oil, peanut oil, soybean oil and lard have been studied by a group of researchers from China. The results indicated that palm oil exhibited the effect of lowering total cholesterol and 'bad' LDL-cholesterol and, yet increasing the level of 'good' HDL-cholesterol. Both peanut oil and soya bean oil had neutral effect on the total cholesterol relative to that of entry levels but lard increases total cholesterol levels.
Among those hypercholesterolemic subjects, palm oil diets decrease the cholesterol levels [2,3]. Cross-over human feeding studies revealed that the total cholesterol, LDL-cholesterol, HDL-cholesterol and triglycerides levels of olive oil and palm oil diets were comparable $[4,5,6]$.

The evergreen olive cultivar (Olea europaea L., Oleaceae) is an important Mediterranean tree. Olive oil is a valuable natural product that provides an excellent and unique flavor and nutritional benefits. Marta and his co-workers (2014) encountered that substantial consumption of total olive oil is correlated with reduced cardiovascular disease and mortality risk in an elderly Mediterranean population, who have relatively higher cardiovascular risk [7]. Olive oil was found to enhance fat oxidation and regulated myocardial metabolic enzymes by optimizing cardiac energy metabolism in obesity conditions. Besides, olive oil and its minor phenolic compounds, oleuropein and caffeic acid were reported to possess myocardial antioxidant activity in standard-fed conditions in previous study [8].

Recent investigations on the effects of ratio of saturated fatty acids (SFA) and unsaturated fatty acids (UFA) on physicochemical properties of palm olein-olive oil blends indicated that the chemical stability of these blends were significantly increased with an increase proportion of palm olein to olive oil content $[9,10]$. The effects of long chain SFAs at $s n-1,3$ positions of triglycerides on the reduction of fat deposition have been reported previously by Smink et al. (2008) and Kronh et al. (2008) [11,12]. 
Therefore, increasing SFAs at $s n-1,3$ positions of triglycerides is expected to affect fat deposition by the blends. Therefore, palm olein-olive oil blends would be as healthy as olive oil in terms of lipid profile. The objective of the experiment was aimed at studying the effects of palm olein-olive oil blends on fat deposition in mice as our knowledge on the partial replacement of palm olein with olive oil on fat deposition is limited.

\section{Materials and Method}

\subsection{Sample Preparation (Blending of Palm Olein and Olive Oil)}

Oil blends were formulated by replacing different proportions of palm olein with olive oil. The palm oleinolive oil blends were prepared at 90:10 (P90), 50:50 (P50) and 10:90 (P10) (w/w). Pure palm olein and olive oil were used as positive and negative controls in this study.

\subsection{Animals and Treatment}

Male C57BL/6 mice were purchased from Sterling Ascent Sdn. Bhd., Malaysia. The mice were housed individually at $22^{\circ} \mathrm{C}, 60 \%$ humidity with a 12-hour light/dark cycle and were fed ad libitum access to water and mice chow without test fats for 2 weeks. The mice were then individually housed at the same condition for 15 weeks. The mice were fed ad libitum access to water and mice chow incorporated with test fats throughout the 15 weeks of experimental period. There were five experimental groups with $\mathrm{n}=8$ animals per group. The sample size was determined by $\mathrm{G}^{*}$ power (version 3.1) analysis program. The test diets were prepared by blending $15 \%(\mathrm{w} / \mathrm{w})$ test fat into the mice chow. The content of the test fats in the blended chow were $15 \mathrm{~g}$ test fats/100 g diet. All test fats were refined, bleached and deodorised without commercial additive. The amount of diets consumed by the mice were measured and calculated using a bench top balance (in grams) daily. The body weights of mice were measured weekly without anaesthesia. The protocol used in this study was approved by the Animal Ethic Committee of Taylor's University with approval number of TUL 2016-001.

\subsection{Serum and Adipose Tissues Preparation}

Overnight fasting blood samples were collected using cardiac puncture method. Serum were then collected by centrifuging the samples at $3500 \mathrm{rpm}$ for 15 minutes and stored at $-80^{\circ} \mathrm{C}$ prior to analysis. Serum leptin levels were performed using mouse/rat leptin Quantikine ELISA kit (R\&D Systems, Minneapolis, MN, USA). Adipose tissues and livers were surgically removed, washed with saline water, wiped with paper towels and weighed during termination.

\subsection{Products Characterisations}

Regio-specific analyses of test fats and extracted lipids from adipose tissues and liver were performed using a NMR spectrometer JEOL ECZ-600MHz [13]. The fatty acid compositions (FAC) of the above samples, extracted lipids from adipose tissues, liver and faeces were analyzed using GC coupled to a mass spectrometer [14]. The tocopherols and tocotrienols of test fats were analyzed using normal phase HPLC coupled to a fluorescence detector [15].

\subsection{Extraction of Lipids from Adipose Tissues, Liver and Faeces}

The extraction of lipids was performed using Folch method [16] with some modifications. Briefly, $60 \mathrm{~mL}$ of the mixture of chloroform and methanol at a 2:1 (v/v) ratio was added into the flask that contained sliced sample. The flask was agitated for 90 minutes in an orbital shaker. The solvent was filtered and $30 \mathrm{~mL}$ of 0.9 wt. $\% \mathrm{NaCl}$ solution was added into the filtrate subsequently to remove nonlipid substances such as amino acids, carbohydrates, urea and salts. The mixture was then transferred into a separating funnel for separation purpose. The extract was evaporated under vacuum in a rotary evaporator to obtain lipids for further analysis.

\subsection{Statistical Analysis}

All the data were presented in mean \pm standard deviations and performed by using statistical analysis software, GraphPad Prism 5. The data were analyzed by one-way analysis of variance (ANOVA), followed by Tukey's Multiple Comparison Test. The $p$ value $<0.05$ was considered to be statistically significant.

\section{Results}

\subsection{Effects of Blends on Total Food Intakes, Body Weight Gain, Adipose Tissue, Liver and Faeces Weights}

There were no significant differences $(p>0.05)$ in initial body weight and food intake observed among the five groups of mice at week-0 (after a 2-week washout period). All the data were normalized with total food intake (15 weeks) to ensure the accuracy of data (Table 1). All the data sets passed D'Agostino and Pearson omnibus and Shapiro-Wilk normality tests $(p>0.05)$ and Bartlett's test for equality of variances $(p>0.05)$. All the normalized data were presented and discussed throughout the manuscript. Mice fed with olive oil group had the highest total body weight gain $\left(5.02 \mathrm{~g} / 10^{-2} \mathrm{~g}\right)$ after the experimental period. In other words, the total body weight gain of the mice fall in the groups that were fed with palm olein $\left(4.51 \mathrm{~g} / 10^{-2} \mathrm{~g}\right)$, P90 (4.87 g/10 $\mathrm{g}), \quad$ P50 (4.81 $\left.\mathrm{g} / 10^{-2} \mathrm{~g}\right)$ and P10 $\left(4.56 \mathrm{~g} / 10^{-2} \mathrm{~g}\right)$ were significantly lower than that fed with olive oil group at $p<0.05$ (Table 1 ).

Besides, the weights of subcutaneous adipose tissue (SAT) of mice fed with palm olein, P90, P50 and P10 were $0.73,0.89,0.79,0.91 \mathrm{~g} / 10^{-2} \mathrm{~g}$, respectively. The results showed that the SAT weights of these mice were lower than the mice fed with olive oil group $\left(0.98 \mathrm{~g} / 10^{-2} \mathrm{~g}\right)$ in which SAT weights of mice fed with palm olein and P50 blend groups were significantly lower than that fed with olive oil group. The weights of total adipose tissue, 
liver and faeces collected from the mice fed with palm olein, P90, P50 and P10 groups were also found to be lower compared with that fed with olive oil. The mice in the palm olein group exhibited the lowest weights in both the total adipose tissue and liver. In contrast, the mice in olive oil group showed the highest weights in total adipose tissues, liver and faeces. The visceral adipose tissue (VAT) weights obtained from the mice fed with palm olein, P90 and P50 were $0.96,0.96$ and $0.97 \mathrm{~g} / 10^{-2} \mathrm{~g}$, respectively. These weights were marginally higher than that of mice fed with P10 $\left(0.89 \mathrm{~g} / 10^{-2} \mathrm{~g}\right)$ and olive oil $\left(0.90 \mathrm{~g} / 10^{-2} \mathrm{~g}\right)$ (Table 1).

\subsection{Effect of Blends on Serum Leptin Levels}

The serum leptin level detected in the mice fed with palm olein $(8.49 \mu \mathrm{g} / \mathrm{dL})$, P90 $(10.41 \mu \mathrm{g} / \mathrm{dL})$ and P50 $(9.94 \mu \mathrm{g} / \mathrm{dL})$ were found to be significantly lower than that fed with olive oil $(12.67 \mu \mathrm{g} / \mathrm{dL})$ at $p<0.05$. In addition, the mice fed with P10 blend also showed lower serum leptin level $(11.30 \mu \mathrm{g} / \mathrm{dL})$ as compared to that fed with olive oil.

\section{Discussion}

Mice are widely used as a research model attributable to their short regeneration time and ease of breeding within the laboratory. Most importantly, the similarities between mice and human in the aspects of their genetic, biological and behaviour characteristics make them appropriate to be used as relevant model in preclinical study [17]. The strain of C57BL/6 is one of the most adaptable inbred mouse and often used as the genetic background for transgenic mouse models. This mice strain is a preferred experimental model for studying atherosclerosis [18], diet-induced obesity [19,20], glucose intolerance [19] and immunology [21]. Thus, C57BL/6 was selected in this study to evaluate the fat deposition in diet-induced obese mice.

The stereospecific structure of triglycerides determines their physical characteristic of fats by affecting the absorption of fatty acids from the gut, lipid metabolism and fat distribution in tissues. Different type of fatty acids attached to the different position of triglycerides results in different digestibility and absorption of these fatty acids, which in turn affecting the cholesterol levels and tissue accumulation of fat [22]. Therefore, lipids of adipose tissues and liver, as well as non-esterified fatty acids (NEFAs) of faeces were analyzed in order to obtain a clearer illustration on the effects of palm olein-olive oil blends on fat deposition in mice.

Adipose tissue is a loose connective tissue containing adipocytes with mesenchymal cell. It is primarily located beneath the skin and surrounding the internal organs such as liver, pancreas and intestines, which are identified as SAT and VAT, respectively. SAT has a better energy storage capacity for its lower metabolic activity compared to that of the VAT. In general, the role of SAT is to accumulate triglycerides during excess energy intake and supply the organism with free fatty acids while fasting, starving or exercising. Both visceral fat and liver play an major role in the development of high fat diet-induced diabetes in mice. VAT is bio-energetically more active and responsive to the substrates of electron transport chain [23]. Liver plays a decisive role in regulating blood cholesterol levels and adipose tissue accumulation and serves as an energy source by oxidizing fatty acids obtained from the blood completely into carbon dioxide and water. It can also convert those fatty acids into ketone bodies which supply extrahepatic tissues with a major energy source, particularly when glucose is limited $[12,24]$. Over $90 \%$ of the dietary fats and lipids are habitually absorbed to the body efficiently. Therefore, faeces generally take up very little undigested fat [25] resulting in the main fatty acids appeared in the faeces to be NEFA [26].

Body weight gain is often associated with obesity and markers of obesity [27]. The total body weight gain of mice was proven to be elevated when olive oil was incorporated in the diets and the results showed significant difference between the mice consuming palm olein and olive oil diets. Previous studies indicated that FAC at $s n-2$ position of triglyceride play an essential role in regulating serum cholesterol levels [22] meanwhile FAC at $s n-1,3$ positions play a crucial role in regulating fat deposition [28]. All the diets used in this study possessed comparable FAC at $s n-2$ position, thus suggesting that the mice would have comparable effects on blood cholesterol levels that have been shown in previous reports $[4,5,13]$. On the other hand, palm olein contains $65.3 \%$ SFA and $34.7 \%$ UFA at $s n-1,3$ positions whereas olive oil contains $30.3 \%$ SFA and $69.7 \%$ UFA at these positions (Table 2), thus revealing that the mice fed with palm olein diets would give lower body weight gain than that of olive oil diets. This statement was proven in this study with significant body weight difference between two diets and hence supported the hypothesis of higher percentage of SFA at $s n-1,3$ positions of triglyceride will contribute to lower fat accretion in the body $[11,12]$.

Our current study revealed that the mice in palm olein group possessed the lowest total adipose fat whereas the mice in olive oil group showed the opposite effect with the highest total adipose fat. Furthermore, the weight of SAT collected from the mice of olive oil group was significantly higher than those of palm olein and P50 groups (Table 1). The results were attributable to types of fatty acid attached to different positions on triglycerides that affected the tissue accumulation of fat and resulted in different digestibility and absorption of fatty acids [22]. The fatty acids absorption rate of mice in palm olein group was much lower than that of olive oil group due to its high percentage of SFA at $s n-1,3$ positions compared to olive oil that contains predominantly mono-unsaturated fatty acids (MUFA) at $s n-1,3$ positions (Table 2). Long chain SFAs are relatively poorer to be absorbed by intestines owing to their higher melting points than body temperature [22]. Instead, SFAs will react rapidly with calcium or magnesium ions in the intestinal lumen and subsequently be excreted from the body in the form of poorly soluble calcium or magnesium fatty acid soaps [29, 30]. Once again, these statements were supported by our current findings where NEFA of palm olein exhibited highest SFA (Table 3). 
Table 1. Normalized data (total body weight gain, adipose tissues weights, liver weights and faeces weights) in mice

\begin{tabular}{lccccc}
\hline & \multicolumn{4}{c}{ Palm Olein:Olive Oil Diets $\left(\mathrm{g} / 10^{-2} \mathrm{~g}\right)$} \\
\cline { 2 - 6 } & $\mathbf{1 0 0 : 0}$ & $\mathbf{9 0 : 1 0}$ & $\mathbf{5 0 : 5 0}$ & $\mathbf{1 0 : 9 0}$ & $\mathbf{0 : 1 0 0}$ \\
\hline Normalized total body weight gain & $4.51 \pm 0.27^{\mathrm{a}}$ & $4.87 \pm 0.35^{\mathrm{a}, \mathrm{b}}$ & $4.81 \pm 0.34^{\mathrm{a}, \mathrm{b}}$ & $4.56 \pm 0.44^{\mathrm{a}, \mathrm{b}}$ & $5.02 \pm 0.32^{\mathrm{b}}$ \\
Normalized total adipose fat & $1.69 \pm 0.13$ & $1.84 \pm 0.22$ & $1.76 \pm 0.20$ & $1.81 \pm 0.12$ & $1.88 \pm 0.15$ \\
Normalized subcutaneous fat & $0.73 \pm 0.08^{\mathrm{a}, \mathrm{c}}$ & $0.89 \pm 0.09^{\mathrm{b}, \mathrm{c}}$ & $0.79 \pm 0.11^{\mathrm{a}, \mathrm{b}, \mathrm{c}}$ & $0.91 \pm 0.08^{\mathrm{b}, \mathrm{c}}$ & $0.98 \pm 0.10^{\mathrm{b}}$ \\
Normalized visceral fat & $0.96 \pm 0.09$ & $0.96 \pm 0.15$ & $0.97 \pm 0.15$ & $0.89 \pm 0.08$ & $0.90 \pm 0.13$ \\
Normalized liver & $0.47 \pm 0.14$ & $0.53 \pm 0.14$ & $0.53 \pm 0.12$ & $0.54 \pm 0.13$ & $0.61 \pm 0.13$ \\
Normalized faeces & $13.54 \pm 0.75$ & $13.08 \pm 0.65$ & $13.87 \pm 0.98$ & $13.42 \pm 1.09$ & $14.08 \pm 0.82$ \\
\hline
\end{tabular}

All data sets passed KS, D'Agostino \& Pearson omnibus and Shapiro-Wilk normality tests $(p>0.05)$. All data sets passed Bartlett's test for equal variances $(p>0.05)$. No significant differences among five groups for normalized total adipose fat, visceral fat, liver and faeces weights. Different letters denote $p<0.05$.

Table 2. Positional fatty acid compositions (mole/100 mole total fatty acids) of test oils

\begin{tabular}{|c|c|c|c|c|}
\hline \multirow[t]{2}{*}{ Groups } & \multirow[t]{2}{*}{ Types of fatty acids } & \multicolumn{3}{|c|}{$\begin{array}{c}\text { Composition } \\
\text { (mole/100 mole total fatty acids) }\end{array}$} \\
\hline & & $s n-1,3$ & $s n-2$ & $s n-1,2,3$ \\
\hline \multirow{3}{*}{ Palm olein } & SFA & $65.3 \pm 2.1$ & $7.6 \pm 0.3$ & $46.7 \pm 1.8$ \\
\hline & MUFA & $29.8 \pm 1.7$ & $67.2 \pm 3.9$ & $41.8 \pm 0.4$ \\
\hline & PUFA & $4.9 \pm 0.4$ & $25.2 \pm 3.7$ & $11.5 \pm 1.6$ \\
\hline \multirow{3}{*}{ P90 } & SFA & $61.0 \pm 4.4$ & $7.4 \pm 2.2$ & $42.6 \pm 4.4$ \\
\hline & MUFA & $32.0 \pm 4.6$ & $68.6 \pm 3.6$ & $44.6 \pm 4.2$ \\
\hline & PUFA & $7.0 \pm 2.2$ & $24.0 \pm 4.8$ & $12.8 \pm 3.2$ \\
\hline \multirow{3}{*}{ P50 } & SFA & $48.5 \pm 0.4$ & $4.1 \pm 1.4$ & $33.8 \pm 0.5$ \\
\hline & MUFA & $42.5 \pm 2.9$ & $72.0 \pm 4.3$ & $52.2 \pm 3.1$ \\
\hline & PUFA & $9.0 \pm 2.6$ & $23.9 \pm 3.7$ & $14.0 \pm 3.1$ \\
\hline \multirow{3}{*}{ P10 } & SFA & $32.8 \pm 3.6$ & $1.3 \pm 1.1$ & $23.3 \pm 2.5$ \\
\hline & MUFA & $56.4 \pm 3.6$ & $73.7 \pm 4.8$ & $61.5 \pm 3.1$ \\
\hline & PUFA & $10.8 \pm 2.4$ & $25.0 \pm 5.4$ & $15.2 \pm 3.6$ \\
\hline \multirow{3}{*}{ Olive oil } & SFA & $30.3 \pm 1.9$ & n.d. & $20.2 \pm 1.4$ \\
\hline & MUFA & $57.4 \pm 3.6$ & $75.2 \pm 3.5$ & $63.3 \pm 3.5$ \\
\hline & PUFA & $12.3 \pm 2.2$ & $24.8 \pm 3.5$ & $16.5 \pm 2.6$ \\
\hline
\end{tabular}

n.d.: Non-detected; SFA: saturated fatty acids; MUFA: monounsaturated fatty acids; PUFA: polyunsaturated fatty acids

Table 3. Total fatty acid compositions (FAC) of faeces ( $\mathrm{g} / \mathbf{1 0 0} \mathrm{g}$ total fatty acids) in mice

\begin{tabular}{cccccc}
\hline FAC & Palm olein & P90 & P50 & P10 & Olive oil \\
\hline C14:0 & $0.82 \pm 0.13$ & $0.78 \pm 0.03$ & $0.66 \pm 0.08$ & $0.40 \pm 0.10$ & $0.37 \pm 0.10$ \\
C16:0 & $37.97 \pm 1.74$ & $36.55 \pm 0.55$ & $28.40 \pm 1.20$ & $21.24 \pm 0.72$ & $19.58 \pm 0.77$ \\
C18:0 & $5.66 \pm 0.24$ & $5.94 \pm 0.21$ & $5.28 \pm 0.20$ & $4.93 \pm 0.37$ & $5.01 \pm 0.21$ \\
C20:0 & $1.53 \pm 0.11$ & $1.59 \pm 0.08$ & $1.71 \pm 0.04$ & $1.82 \pm 0.19$ & $1.85 \pm 0.10$ \\
C22:0 & $0.52 \pm 0.05$ & $0.63 \pm 0.05$ & $0.69 \pm 0.09$ & $0.82 \pm 0.11$ & $0.92 \pm 0.10$ \\
C24:0 & $0.35 \pm 0.09$ & $0.41 \pm 0.13$ & $0.35 \pm 0.04$ & $0.38 \pm 0.11$ & $0.60 \pm 0.09$ \\
\hline C16:1 & $0.41 \pm 0.27$ & $0.53 \pm 0.04$ & $0.86 \pm 0.03$ & $1.37 \pm 0.12$ & $1.33 \pm 0.10$ \\
C18:1 & $36.19 \pm 1.50$ & $36.42 \pm 0.56$ & $43.39 \pm 1.37$ & $49.04 \pm 1.43$ & $49.78 \pm 1.72$ \\
C22:1 & n.d. & $0.06 \pm 0.07$ & $0.03 \pm 0.06$ & $0.09 \pm 0.11$ & $0.10 \pm 0.07$ \\
\hline C18:2 & $15.77 \pm 0.68$ & $16.16 \pm 0.50$ & $17.67 \pm 0.19$ & $18.73 \pm 1.22$ & $19.21 \pm 0.44$ \\
C18:3 & $0.78 \pm 0.08$ & $0.93 \pm 0.08$ & $0.96 \pm 0.13$ & $1.18 \pm 0.08$ & $1.25 \pm 0.07$ \\
\hline SFA & $46.85 \pm 1.84$ & $45.90 \pm 0.49$ & $37.09 \pm 1.37$ & $29.59 \pm 0.63$ & $28.33 \pm 1.27$ \\
MUFA & $36.60 \pm 1.25$ & $37.01 \pm 0.53$ & $44.28 \pm 1.35$ & $50.50 \pm 1.51$ & $51.21 \pm 1.75$ \\
PUFA & $16.55 \pm 0.69$ & $17.09 \pm 0.56$ & $18.63 \pm 0.07$ & $19.91 \pm 1.22$ & $20.46 \pm 0.49$ \\
\hline
\end{tabular}

n.d.: Non-detected; SFA: saturated fatty acids; MUFA: monounsaturated fatty acids; PUFA: polyunsaturated fatty acids.

Both SAT and VAT contained relatively identical positional fatty acid distribution and FAC profiles within groups because both the adipose tissues function as energy storage [23,31] (Table 4 and Table 5). The positional fatty acid distribution and FAC profiles of liver fats did not differ among the five groups (Table 6). Interestingly, the SFA of liver fats collected from the mice fed with palm olein,
P90 and P50 attached at $s n-1,3$ positions of triglycerides were remarkably lower than that of the respective diets (Table 2) while the SFA of liver fats belong to the mice in P10 and olive oil groups were higher than that of the diets. P10 and olive oil diets contained primarily UFAs which were consequently hydrogenated to SFA and our findings were well supported by the literature data [32]. 
Table 4. Positional fatty acid compositions (mole/100 mole total fatty acids) of SAT in mice

\begin{tabular}{|c|c|c|c|c|}
\hline \multirow{2}{*}{ Groups } & \multirow{2}{*}{ Types of fatty acids } & \multicolumn{3}{|c|}{$\begin{array}{c}\text { Composition } \\
\text { (mole/100 mole total fatty acids) }\end{array}$} \\
\hline & & $s n-1,3$ & $s n-2$ & $s n-1,2,3$ \\
\hline \multirow{3}{*}{ Palm olein } & SFA & $38.5 \pm 0.9$ & $7.9 \pm 1.8$ & $28.3 \pm 0.2$ \\
\hline & MUFA & $57.0 \pm 1.3$ & $66.3 \pm 1.6$ & $60.1 \pm 1.5$ \\
\hline & PUFA & $4.5 \pm 1.5$ & $25.8 \pm 2.9$ & $11.6 \pm 1.5$ \\
\hline \multirow{3}{*}{ P90 } & SFA & $37.6 \pm 1.4$ & $5.0 \pm 2.2$ & $26.9 \pm 0.1$ \\
\hline & MUFA & $57.6 \pm 1.8$ & $67.7 \pm 4.4$ & $60.9 \pm 2.5$ \\
\hline & PUFA & $4.8 \pm 1.1$ & $27.3 \pm 5.6$ & $12.2 \pm 2.4$ \\
\hline \multirow{3}{*}{ P50 } & SFA & $31.6 \pm 1.5$ & $2.9 \pm 2.6$ & $22.0 \pm 1.0$ \\
\hline & MUFA & $61.1 \pm 1.2$ & $67.6 \pm 5.1$ & $63.3 \pm 2.1$ \\
\hline & PUFA & $7.3 \pm 0.6$ & $29.5 \pm 2.9$ & $14.7 \pm 1.4$ \\
\hline \multirow{3}{*}{ P10 } & SFA & $27.2 \pm 0.4$ & $2.6 \pm 2.4$ & $19.1 \pm 0.7$ \\
\hline & MUFA & $66.4 \pm 0.5$ & $71.3 \pm 4.2$ & $68.0 \pm 1.9$ \\
\hline & PUFA & $6.4 \pm 0.1$ & $26.1 \pm 3.9$ & $12.9 \pm 1.3$ \\
\hline \multirow{3}{*}{ Olive oil } & SFA & $24.6 \pm 0.7$ & n.d. & $16.8 \pm 0.6$ \\
\hline & MUFA & $66.9 \pm 4.1$ & $70.2 \pm 4.5$ & $67.9 \pm 4.3$ \\
\hline & PUFA & $8.5 \pm 4.3$ & $29.8 \pm 4.5$ & $15.3 \pm 4.5$ \\
\hline
\end{tabular}

n.d.: Non-detected; SFA: saturated fatty acids; MUFA: monounsaturated fatty acids; PUFA: polyunsaturated fatty acids

Table 5. Positional fatty acid compositions (mole/100 mole total fatty acids) of VAT in mice

\begin{tabular}{|c|c|c|c|c|}
\hline \multirow[t]{2}{*}{ Groups } & \multirow[t]{2}{*}{ Types of fatty acids } & \multicolumn{3}{|c|}{$\begin{array}{c}\text { Composition } \\
\text { (mole/100 mole total fatty acids) }\end{array}$} \\
\hline & & $s n-1,3$ & $s n-2$ & $s n-1,2,3$ \\
\hline \multirow{3}{*}{ Palm olein } & SFA & $37.3 \pm 2.0$ & $7.2 \pm 1.9$ & $27.3 \pm 1.5$ \\
\hline & MUFA & $57.0 \pm 3.5$ & $63.7 \pm 2.4$ & $59.2 \pm 3.1$ \\
\hline & PUFA & $5.7 \pm 3.6$ & $29.2 \pm 4.0$ & $13.5 \pm 3.6$ \\
\hline \multirow{3}{*}{ P90 } & SFA & $36.1 \pm 1.7$ & $5.6 \pm 0.9$ & $26.1 \pm 1.1$ \\
\hline & MUFA & $56.4 \pm 2.7$ & $66.1 \pm 4.2$ & $59.6 \pm 3.8$ \\
\hline & PUFA & $7.5 \pm 4.4$ & $28.3 \pm 6.0$ & $14.3 \pm 4.9$ \\
\hline \multirow{3}{*}{ P50 } & SFA & $33.7 \pm 0.9$ & $3.3 \pm 3.0$ & $23.8 \pm 1.1$ \\
\hline & MUFA & $56.5 \pm 4.2$ & $63.2 \pm 7.3$ & $58.7 \pm 4.0$ \\
\hline & PUFA & $9.8 \pm 4.0$ & $33.5 \pm 6.3$ & $17.6 \pm 3.4$ \\
\hline \multirow{3}{*}{ P10 } & SFA & $28.1 \pm 1.4$ & n.d. & $19.8 \pm 0.7$ \\
\hline & MUFA & $57.1 \pm 4.4$ & $71.9 \pm 4.7$ & $61.4 \pm 3.7$ \\
\hline & PUFA & $14.8 \pm 4.0$ & $28.1 \pm 4.3$ & $18.8 \pm 3.4$ \\
\hline \multirow{3}{*}{ Olive oil } & SFA & $27.5 \pm 2.0$ & n.d. & $18.4 \pm 1.8$ \\
\hline & MUFA & $62.8 \pm 2.1$ & $69.3 \pm 3.2$ & $64.9 \pm 1.8$ \\
\hline & PUFA & $9.7 \pm 2.1$ & $30.7 \pm 3.2$ & $16.7 \pm 3.0$ \\
\hline
\end{tabular}

n.d.: Non-detected; SFA: saturated fatty acids; MUFA: monounsaturated fatty acids; PUFA: polyunsaturated fatty acids

Table 6. Positional fatty acid compositions (mole/100 mole total fatty acids) of liver in mice

\begin{tabular}{|c|c|c|c|c|}
\hline \multirow[t]{2}{*}{ Groups } & \multirow{2}{*}{ Types of fatty acids } & \multicolumn{3}{|c|}{$\begin{array}{c}\text { Composition } \\
\text { (mole/100 mole total fatty acids) }\end{array}$} \\
\hline & & $s n-1,3$ & $s n-2$ & $s n-1,2,3$ \\
\hline \multirow{3}{*}{ Palm olein } & SFA & $43.3 \pm 4.1$ & $2.8 \pm 2.4$ & $30.6 \pm 4.1$ \\
\hline & MUFA & $44.7 \pm 4.8$ & $65.3 \pm 4.6$ & $51.2 \pm 4.6$ \\
\hline & PUFA & $12.0 \pm 1.7$ & $31.9 \pm 4.0$ & $18.2 \pm 1.7$ \\
\hline \multirow{3}{*}{ P90 } & SFA & $38.5 \pm 2.4$ & $1.0 \pm 1.7$ & $27.4 \pm 1.7$ \\
\hline & MUFA & $47.9 \pm 4.2$ & $72.8 \pm 3.2$ & $55.2 \pm 4.6$ \\
\hline & PUFA & $13.6 \pm 4.7$ & $26.2 \pm 4.0$ & $17.4 \pm 3.7$ \\
\hline \multirow{3}{*}{ P50 } & SFA & $40.2 \pm 3.2$ & n.d. & $27.5 \pm 2.3$ \\
\hline & MUFA & $47.4 \pm 4.6$ & $74.1 \pm 4.0$ & $55.8 \pm 4.1$ \\
\hline & PUFA & $12.4 \pm 3.7$ & $25.9 \pm 4.0$ & $16.7 \pm 4.3$ \\
\hline \multirow{3}{*}{ P10 } & SFA & $38.8 \pm 3.7$ & n.d. & $26.2 \pm 2.8$ \\
\hline & MUFA & $43.4 \pm 3.9$ & $72.2 \pm 2.9$ & $52.7 \pm 3.5$ \\
\hline & PUFA & $17.8 \pm 3.6$ & $27.8 \pm 2.9$ & $21.1 \pm 3.3$ \\
\hline \multirow{3}{*}{ Olive oil } & SFA & $39.3 \pm 3.8$ & n.d. & $26.4 \pm 2.5$ \\
\hline & MUFA & $48.8 \pm 4.0$ & $74.6 \pm 4.7$ & $57.3 \pm 2.7$ \\
\hline & PUFA & $11.9 \pm 1.6$ & $25.4 \pm 4.7$ & $16.3 \pm 1.9$ \\
\hline
\end{tabular}

n.d.: Non-detected; SFA: saturated fatty acids; MUFA: monounsaturated fatty acids; PUFA: polyunsaturated fatty acids 
Leptin is a hormone secreted by adipocytes that plays an important role in regulating energy balance to control body weight and the sensation of hunger. Excess level of serum leptin in circulation is often associated with an increased risk of obesity [33,34]. This statement is supported by previous findings that obese individuals have higher circulating leptin levels, indicating that serum leptin levels and body fat percentage are positively correlated [35]. In our current study, the results for serum leptin concentration demonstrated that the mice fed with olive oil diets exhibited significantly higher serum leptin concentrations than that of the mice fed with palm olein, P90 and P50 diets, revealing that the mice in olive oil group had the highest percentage of body fat. Apart from that, palm olein and the three diets (P90, P50 and P10) possessed substantially higher concentrations of tocotrienols (T3), specifically $\alpha$-T3, $\beta$-T3, $\gamma$-T3 and $\delta$-T3, which have been reported to exert anti-oxidant and natural inhibitors of cholesterol synthesis, if compared to olive oil [1].

\section{Conclusion}

Overall, our findings demonstrated that the mice in palm olein and the other three blends (P90, P50 and P10) groups developed lesser body fat accumulation than those in olive oil group, based on the measured parameters of total body weight gain, total adipose tissue, liver fat and serum leptin levels.

\section{Conflict of Interest}

None of the authors had a conflict of interest.

\section{Acknowledgement}

We would like to thank the Director General of MPOB for permission to publish these data. This research was supported by the Malaysian Palm Oil Board.

\section{References}

[1] Pearce, B.C., Parker, R.A., Deason, M.E., Dischino, D.D., Gillespie, E., Qureshi, A.A., Volk, K. and Wright, J.J. (1994). Inhibitors of cholesterol biosynthesis. 2. Hypocholesterolemic and antioxidant activities of benzopyran and tetrahydronaphthalene analogues of the tocotrienols. Journal of Medicinal Chemistry 37 (4): 526-541.

[2] Zhang, J., Wang, P., Wang, C., Chen, X.S. and Ge, K. (1997). Nonhypercholesterolemic effects of a palm oil diet in Chinese adults. Journal of Nutrition 127 (3): 509S-513S.

[3] Zhang, J., Wang, P., Dai, J., Chen, X.S. and Ge, K.Y. (1997). Palm oil diet may benefit mildly hypercholesterolemic Chinese adults. Asia Pacific Journal of Clinical Nutrition 6 (1): 22-25.

[4] Choudhury, N., Tan, L. and Truswell, A.S. (1995). Comparison of palm olein and olive oil: effects on plasma lipids and vitamin E in young adults. American Journal of Clinical Nutrition 61: 10431051 .

[5] Ng, T.K.W., Hayes, K.C., DeWitt, G.F., Jegathesan, M., Path, F., Satgunasingam, N., Ong, A.S.H. and Tan, D. (1992). Dietary palmitic and oleic acids exert similar effects on serum cholesterol and lipoprotein profiles in normocholesterolemic men and women. Journal of American College of Nutrition 11 (4): 383-390.
[6] Voon, P.T., Ng, T.K.W., Lee, V.K.M.L. and Nesaretnam, K. (2011). Diets high in palmitic acid (16:0), lauric and myristic acids $(12: 0+14: 0)$, or oleic acid (18:1) do not alter postprandial or fasting plasma homocysteine and inflammatory markers in healthy Malaysian adults. American Journal of Clinical Nutrition 94: 1451-1457.

[7] Marta, G.F., Frank, B.H., Miguel, A.M.G., Montserrat, F., Monica, B., Ramon, E., Emilio, R., Dolores, C., Javier, R., Enrique, G.G., Miguel, F., Jose, L., Lluis, S.M. and et al (2014). Olive oil intake and risk of cardiovascular disease and mortality in the PREDIMED Study. BMC Medicine 12: 78-88.

[8] Ebaid, G.M.X., Seiva, F.R.F., Rocha, K.K.H.R., Souza, G.A. and Novelli, E.L.B. (2010). Effects of olive oil and its minor phenolic constituents on obesity-induced cardiac metabolic changes. Nutrition Journal 9: 46-54.

[9] Naghshineh, M., Ariffin, A.A., Ghazali, H., Mirhosseini, H. and Mohammad, A.S. (2010). Effect of saturated/unsaturated fatty acid ratio on physicochemical properties of palm olein-olive oil blend. Journal of the American Oil Chemists' Society 87: 255-262.

[10] Naghshineh, M. and Mirhosseini, H. (2010). Effects of frying condition on physicochemical properties of palm olein-olive oil blends. Journal of Food, Agriculture \& Environment 8 (3\&4): $175-178$.

[11] Smink, W., Gerrits, W.J.J., Hovenier, R., Geelen, M.J.H., Lobee, H.W.J., Verstegen, M.W.A. and Beynen, A.C. (2008). Fatty acid digestion and deposition in boiler chickens fed diets containing either native or randomized palm oil. Poultry Science 87: 506-513.

[12] Krohn, K., Demmelmair, H. and Koletzko, B. (2008). Chapter 7: Macronutrient requirements for growth: Fats and fatty acids. In Nutrition in Pediatrics: Basic Science, Clinical Applications, Duggan, C., Watkins, J.B. and Walker, A.W., Ed., 2008; Vol.4. pp. 59-65.

[13] Teh, S.S., Voon, P.T., Ng, Y.T., Ong, S.H., Ong, A.S.H. and Choo, Y.M. (2016). Effects of fatty acids at different positions in the triglycerides on cholesterol levels. Journal of Oil Palm Research 28 (2): 211-221.

[14] Teh, S.S., Voon, P.T., Ong, A.S.H. and Choo, Y.M. (2016). Incorporation of Palmitic Acid or Stearic Acid into Soybean Oils Using Enzymatic Interesterification. Journal of Oleo Science 65 (9): 797-802.

[15] Che, H.L., Tan, D.M.Y., Meganathan, P., Gan, Y.L., Razak, G.A. and Fu, J.Y. (2015). Validation of a HPLC/FLD Method for quantification of tocotrienols in human plasma. International Journal of Analytical Chemistry 2015: 1-7.

[16] Folch, J., Lees, M. and Stanley, G.H.S. (1957). A Simple Method for the Isolation and Purification of Total Lipides from Animal Tissues. Journal of Biological Chemistry 226: 497-509.

[17] Monaco, G., Dam, S., Ribeiro, J.L.C.N., Larbi, A. and Magalhaes, J.P. (2015). A comparison of human and mouse gene coexpression networks reveals conservation and divergence at the tissue, pathway and disease levels. BMC Evolutionary Biology 15 : 259-272.

[18] Emeson, E.E. and Shen, M.L. (1993). Accelerated atherosclerosis in hyperlipidemic $\mathrm{C} 57 \mathrm{BL} / 6$ mice treated with cyclosporin A. American Journal of Pathology 142 (6): 1906-1915.

[19] Parekh, P.I., Petro, A.E., Tiller, J.M., Feinglos, M.N. and Surwit, R.S. (1998). Reversal of diet-induced obesity and diabetes in C57BL/6J mice. Metabolism 47 (9): 1089-1096.

[20] Nicholson, A., Reifsnyder, P.C., Malcolm, R.D., Lucas, C.A., MacGregor, G.R., Zhang, W. and Leiter, E.H. (2010). Dietinduced obesity in two C57BL/6 substrains with intact or mutant nicotinamide nucleotide transhydrogenase (Nnt) gene. Obesity 18 (10): 1902-1905.

[21] Brooke, M.S. (1965). The immunological behaviour of mature C57BL-6J mice thymectomized at birth. Immunology 8 (5): 526528.

[22] Small, D.M. (1991). The effects of glyceride structure on absorption and metabolism. Annual Review of Nutrition 11: 413434.

[23] Cederberg, H. and Laakso, M. (2014). Chapter 49: Obesity and Type 2 Diabetes. In Handbook of Obesity: Epidemiology, Etiology, and Physiopathology, Bray, G.A. and Bouchard, C., Ed. 2014; Vol. 1. pp 539-548.

[24] Manninen, A.H. (2004). Metabolic effects of the very-lowcarbohydrate diets: Misunderstood "Villains" of human metabolism. Journal of International Society of Sports Nutrition 1 (2): 7-11. 
[25] Carey, M.C., Small, D.M. and Bliss, C.M. (1983). Lipid digestion and absorption. Annual Review of Physiology 45: 651-677.

[26] Verdonk, G., Christophe, A., Mortelmans, R. and Vandevivere, D (1978). Chapter 18: Possibilities of semi-synthetic fats for human nutrition and dietetics: New concepts in the physio-pathology of lipid assimilation. In The Pharmacological Effect of Lipids, Kabara, J.J., Ed. 1978; pp191-202.

[27] Sacco, M.R., Castro, N.P., Euclydes, V.L., Souza, J.M. and Rondo, P.H. (2013). Birth weight, rapid weight gain in infancy and markers of overweight and obesity in childhood. European Journal of Clinical Nutrition 67 (11): 1147-1153.

[28] Mattson, F.H. and Volpenhein, R.A. (1964). The digestion and absorption in triglycerides. Journal of Biological Chemistry 239 (9): 2772-2777.

[29] Mattson, F.H., Nolen, G.A. and Webb, M.R. (1979). The absorbability by rats of various triglycerides of stearic and oleic acid and the effect of dietary calcium and magnesium. Journal of Nutrition 109 (10): 1682-1687.

[30] Brink, E.J., Haddeman, E., Fouw, N.J. and Weststrate, J.A. (1995). Positional distribution of stearic acid and oleic acid in a triacylglycerol and dietary calcium concentration determines the apparent absorption of these fatty acids in rats. Journal of Nutrition 125 (9): 2379-2387.
[31] Lehner, R. and Kuksis, A. (1996). Biosynthesis of triacylglycerols. Prog. Lipid Res. 35 (2): 169-201.

[32] Gurr, M.I. (2013). Chapter 1: The chemistry and biochemistry of plant fats and their nutritional importance. In Fats in Animal Nutrition, Wiseman, J., Ed. 2013; pp 3-22.

[33] Tartaglia, L.A., Dembski, M., Weng, X., Deng, N., Culpepper, J., Devos, R., G.J., R., Campfield, L.A., Clark, F.T., Deeds, J., Muir, C., Sanker, S., Moriarty, A., Moore, K.J., Smutko, J.S., Mays, G.G., Wool, E.A., Monroe, C.A. and Tepper, R.I. (1995). Identification and expression cloning of a leptin receptor, OB-R. Cell Press 83 (7): 1263-1271.

[34] Chen, H., Charlat, O., Tartaglia, L.A., Woolf, E.A., Weng, X., Ellis, S.J., Lakey, N.D., Culpepper, J., Moore, K.J., Breitbart, R.E., Duyk, G.M., Tepper, R.I. and Morgenstern, J.P. (1996). Evidence that the diabetes gene encodes the leptin receptor: identification of a mutation in the leptin receptor gene in $\mathrm{db} / \mathrm{db}$ mice. Cell Press 84 (3): 491-495.

[35] Considine, R.V., Sinha, M.K., Heiman, M.L., Kriauciunas, A., Stephens, T.W., Nyce, M.R., Ohannesian, J.P., Marco, C.C., McKee, L.J., Bauer, T.L. and et al. (1996). Serum immunoreactiveleptin concentrations in normal-weight and obese humans. New England Journal of Medicine 334 (5): 292-295.

\section{Supplementary Material}

Table S1. Total fatty acid compositions (FAC) of test oils ( $\mathrm{g} / 100 \mathrm{~g}$ total fatty acids)

\begin{tabular}{cccccc}
\hline FAC & Palm olein & P90 & P50 & P10 & Olive oil \\
\hline C12:0 & $0.10 \pm 0.03$ & $0.09 \pm 0.00$ & $0.06 \pm 0.01$ & n.d. & n.d. \\
C14:0 & $0.89 \pm 0.34$ & $0.78 \pm 0.01$ & $0.44 \pm 0.01$ & $0.09 \pm 0.03$ & n.d. \\
C16:0 & $40.15 \pm 0.08$ & $37.84 \pm 0.02$ & $28.66 \pm 0.04$ & $19.89 \pm 0.05$ & $17.47 \pm 0.05$ \\
C18:0 & $4.07 \pm 0.79$ & $3.73 \pm 0.02$ & $3.20 \pm 0.02$ & $2.48 \pm 0.02$ & $2.31 \pm 0.02$ \\
C20:0 & $0.21 \pm 0.12$ & $0.20 \pm 0.01$ & $0.22 \pm 0.01$ & $0.14 \pm 0.02$ & $0.10 \pm 0.03$ \\
C16:1 & $0.13 \pm 0.08$ & $0.27 \pm 0.00$ & $0.89 \pm 0.01$ & $1.62 \pm 0.01$ & $1.79 \pm 0.00$ \\
C18:1 & $43.37 \pm 0.62$ & $45.53 \pm 0.02$ & $53.26 \pm 0.04$ & $60.42 \pm 0.07$ & $62.70 \pm 0.05$ \\
C18:2 & $10.93 \pm 0.40$ & $11.36 \pm 0.02$ & $12.91 \pm 0.02$ & $14.84 \pm 0.04$ & $15.15 \pm 0.02$ \\
C18:3 & $0.15 \pm 1.06$ & $0.20 \pm 0.00$ & $0.36 \pm 0.01$ & $0.53 \pm 0.05$ & $0.48 \pm 0.01$ \\
\hline SFA & $45.42 \pm 0.05$ & $42.64 \pm 0.03$ & $32.58 \pm 0.06$ & $22.60 \pm 0.03$ & $19.88 \pm 0.05$ \\
MUFA & $43.50 \pm 0.06$ & $45.80 \pm 0.02$ & $54.14 \pm 0.05$ & $62.04 \pm 0.06$ & $64.49 \pm 0.05$ \\
PUFA & $11.08 \pm 0.01$ & $11.56 \pm 0.02$ & $13.28 \pm 0.02$ & $15.37 \pm 0.09$ & $15.63 \pm 0.01$ \\
\hline
\end{tabular}

n.d.: Non-detected; SFA: saturated fatty acids; MUFA: monounsaturated fatty acids; PUFA: polyunsaturated fatty acids.

Table S2. Vitamin E content of test oils $(\mu \mathrm{g} / \mathrm{g})$

\begin{tabular}{lccccc}
\hline Types of Vitamin E & Palm olein & P90 & P50 & P10 & Olive oil \\
\hline Alpha-tocopherol & $118.24 \pm 1.73$ & $120.3 \pm 0.25$ & $119.31 \pm 1.27$ & $125.77 \pm 2.99$ & $122.23 \pm 0.76$ \\
Alpha-tocotrienol & $179.72 \pm 2.75$ & $164.49 \pm 0.06$ & $92.62 \pm 1.02$ & $21.18 \pm 0.47$ & n.d. \\
Beta-tocopherol & $1.54 \pm 0.01$ & $1.62 \pm 0.06$ & $2.00 \pm 0.01$ & $2.48 \pm 0.02$ & $2.48 \pm 0.01$ \\
Gamma-tocopherol & $1.33 \pm 0.01$ & $2.49 \pm 0.05$ & $7.29 \pm 0.08$ & $12.41 \pm 0.17$ & $13.01 \pm 0.06$ \\
Beta-tocotrienol & $14.3 \pm 0.20$ & $13.11 \pm 0.06$ & $7.35 \pm 0.08$ & $2.34 \pm 0.02$ & n.d. \\
Gamma-tocotrienol & $239.2 \pm 3.29$ & $219.78 \pm 0.59$ & $118.16 \pm 1.10$ & $25.31 \pm 0.54$ & $0.95 \pm 0.01$ \\
Delta-tocopherol & $0.85 \pm 0.04$ & $0.93 \pm 0.09$ & $1.11 \pm 0.06$ & $1.23 \pm 0.33$ & $1.13 \pm 0.11$ \\
Delta-tocotrienol & $84.42 \pm 0.25$ & $76.6 \pm 0.37$ & $42.14 \pm 0.29$ & $8.86 \pm 0.33$ & n.d. \\
\hline Total (ugg/g) & $639.61 \pm 4.28$ & $599.32 \pm 1.42$ & $389.98 \pm 3.90$ & $199.58 \pm 4.18$ & $139.8 \pm 0.74$ \\
\hline
\end{tabular}

n.d.: Non-detected. 
Table S3. Body weight, total body weight gain, total food intake, adipose tissues weights, liver weights and faeces weights in mice

\begin{tabular}{|c|c|c|c|c|c|c|}
\hline & & \multicolumn{5}{|c|}{ Palm Olein: Olive Oil Diets } \\
\hline & & 100:0 & 90:10 & 50:50 & 10:90 & 0:100 \\
\hline \multirow{2}{*}{ Body weight (g) } & Initial (week-0) & $21.38 \pm 1.36$ & $21.68 \pm 1.49$ & $21.53 \pm 1.54$ & $21.34 \pm 1.10$ & $21.56 \pm 0.98$ \\
\hline & Final (week-15) & $40.44 \pm 3.22$ & $41.95 \pm 2.56$ & $41.31 \pm 3.05$ & $41.50 \pm 2.19$ & $42.04 \pm 2.84$ \\
\hline \multicolumn{2}{|c|}{ Total body weight gain } & $19.06 \pm 2.03$ & $20.27 \pm 1.51$ & $19.78 \pm 2.05$ & $20.16 \pm 2.38$ & $20.50 \pm 2.10$ \\
\hline \multicolumn{2}{|l|}{ Total food intake } & $422.7 \pm 34.3$ & $416.6 \pm 22.9$ & $411.3 \pm 26.8$ & $441.9 \pm 24.0$ & $408.3 \pm 26.6$ \\
\hline \multicolumn{2}{|l|}{ Food intake $(\mathrm{g} / \mathrm{d})$} & $4.02 \pm 0.30$ & $3.90 \pm 0.28$ & $3.94 \pm 0.24$ & $4.13 \pm 0.26$ & $3.88 \pm 0.23$ \\
\hline \multicolumn{2}{|l|}{ Total adipose fat } & $7.13 \pm 0.70$ & $7.67 \pm 0.90$ & $7.23 \pm 0.68$ & $7.96 \pm 0.43$ & $7.64 \pm 0.47$ \\
\hline \multicolumn{2}{|l|}{ Subcutaneous fat } & $3.08 \pm 0.36$ & $3.70 \pm 0.45$ & $3.27 \pm 0.51$ & $4.01 \pm 0.26$ & $3.99 \pm 0.47$ \\
\hline \multicolumn{2}{|l|}{ Visceral fats } & $4.05 \pm 0.49$ & $3.97 \pm 0.56$ & $3.96 \pm 0.42$ & $3.95 \pm 0.34$ & $3.65 \pm 0.42$ \\
\hline \multicolumn{2}{|l|}{ Liver } & $2.03 \pm 0.72$ & $2.20 \pm 0.65$ & $2.21 \pm 0.61$ & $2.40 \pm 0.65$ & $2.52 \pm 0.68$ \\
\hline \multicolumn{2}{|l|}{ Faeces weight } & $57.16 \pm 4.64$ & $54.44 \pm 3.40$ & $57.53 \pm 5.75$ & $59.18 \pm 3.96$ & $57.46 \pm 4.22$ \\
\hline
\end{tabular}

Food intake $p>0.05$. After normalization with total food intake.

Table S4. Total fatty acid compositions (FAC) of SAT ( $\mathrm{g} / 100 \mathrm{~g}$ total fatty acids) in mice

\begin{tabular}{|c|c|c|c|c|c|}
\hline FAC & Palm olein & P90 & P50 & P10 & Olive oil \\
\hline C14:0 & $0.58 \pm 0.06$ & $0.54 \pm 0.07$ & $0.45 \pm 0.06$ & $0.37 \pm 0.05$ & $0.34 \pm 0.03$ \\
\hline C16:0 & $23.11 \pm 0.37$ & $22.20 \pm 0.50$ & $18.99 \pm 0.58$ & $15.44 \pm 0.18$ & $14.68 \pm 0.22$ \\
\hline C18:0 & $1.70 \pm 0.09$ & $1.71 \pm 0.07$ & $1.71 \pm 0.08$ & $1.74 \pm 0.05$ & $1.73 \pm 0.05$ \\
\hline C20:0 & $0.40 \pm 0.05$ & $0.39 \pm 0.06$ & $0.39 \pm 0.06$ & $0.47 \pm 0.08$ & $0.45 \pm 0.05$ \\
\hline C16:1 & $5.18 \pm 0.39$ & $4.80 \pm 0.33$ & $4.07 \pm 0.33$ & $3.61 \pm 0.25$ & $3.47 \pm 0.14$ \\
\hline C18:1 & $55.60 \pm 1.07$ & $57.10 \pm 1.30$ & $60.88 \pm 0.96$ & $63.78 \pm 1.00$ & $64.77 \pm 0.48$ \\
\hline C18:2 & $13.35 \pm 0.34$ & $13.18 \pm 0.44$ & $13.42 \pm 0.85$ & $14.49 \pm 0.50$ & $14.47 \pm 0.27$ \\
\hline C18:3 & $0.08 \pm 0.04$ & $0.08 \pm 0.03$ & $0.09 \pm 0.01$ & $0.10 \pm 0.01$ & $0.09 \pm 0.01$ \\
\hline SFA & $25.79 \pm 0.52$ & $24.84 \pm 0.66$ & $21.54 \pm 0.69$ & $18.02 \pm 0.29$ & $17.20 \pm 0.25$ \\
\hline MUFA & $60.78 \pm 0.77$ & $61.90 \pm 1.02$ & $64.95 \pm 0.88$ & $67.39 \pm 0.76$ & $68.24 \pm 0.37$ \\
\hline PUFA & $13.43 \pm 0.35$ & $13.26 \pm 0.46$ & $13.51 \pm 0.85$ & $14.59 \pm 0.50$ & $14.56 \pm 0.27$ \\
\hline & 100.00 & 100.00 & 100.00 & 100.00 & 100.00 \\
\hline
\end{tabular}

SFA: saturated fatty acids; MUFA: monounsaturated fatty acids; PUFA: polyunsaturated fatty acids.

Table S5. Total fatty acid compositions (FAC) of VAT ( $\mathrm{g} / 100 \mathrm{~g}$ total fatty acids) in mice

\begin{tabular}{|c|c|c|c|c|c|}
\hline FAC & Palm olein & P90 & P50 & P10 & Olive oil \\
\hline C14:0 & $0.63 \pm 0.02$ & $0.59 \pm 0.05$ & $0.51 \pm 0.05$ & $0.42 \pm 0.02$ & $0.39 \pm 0.02$ \\
\hline C16:0 & $23.78 \pm 0.17$ & $22.55 \pm 0.56$ & $20.16 \pm 0.95$ & $16.99 \pm 0.60$ & $16.58 \pm 0.26$ \\
\hline C18:0 & $1.60 \pm 0.04$ & $1.60 \pm 0.04$ & $1.67 \pm 0.05$ & $1.65 \pm 0.07$ & $1.67 \pm 0.03$ \\
\hline C20:0 & $0.45 \pm 0.05$ & $0.41 \pm 0.07$ & $0.35 \pm 0.13$ & $0.43 \pm 0.10$ & $0.28 \pm 0.03$ \\
\hline C16:1 & $6.10 \pm 0.44$ & $5.62 \pm 0.42$ & $4.63 \pm 0.27$ & $4.19 \pm 0.23$ & $4.01 \pm 0.11$ \\
\hline C18:1 & $53.84 \pm 0.78$ & $56.04 \pm 1.52$ & $60.28 \pm 2.01$ & $62.98 \pm 1.23$ & $65.31 \pm 0.60$ \\
\hline C18:2 & $13.50 \pm 0.24$ & $13.10 \pm 0.47$ & $12.30 \pm 1.53$ & $13.24 \pm 1.13$ & $11.65 \pm 0.35$ \\
\hline C18:3 & $0.10 \pm 0.01$ & $0.09 \pm 0.01$ & $0.10 \pm 0.01$ & $0.10 \pm 0.01$ & $0.11 \pm 0.00$ \\
\hline SFA & $26.46 \pm 0.19$ & $25.15 \pm 0.67$ & $22.69 \pm 1.06$ & $19.49 \pm 0.66$ & $18.92 \pm 0.30$ \\
\hline MUFA & $59.94 \pm 0.37$ & $61.66 \pm 1.10$ & $64.91 \pm 1.80$ & $67.17 \pm 1.05$ & $69.32 \pm 0.51$ \\
\hline PUFA & $13.60 \pm 0.24$ & $13.19 \pm 0.46$ & $12.40 \pm 1.52$ & $13.34 \pm 1.12$ & $11.76 \pm 0.35$ \\
\hline
\end{tabular}

SFA: saturated fatty acids; MUFA: monounsaturated fatty acids; PUFA: polyunsaturated fatty acids. 
Table S6. Total fatty acid compositions (FAC) of liver ( $\mathrm{g} / 100 \mathrm{~g}$ total fatty acids) in mice

\begin{tabular}{|c|c|c|c|c|c|}
\hline FAC & Palm olein & P90 & P50 & P10 & Olive oil \\
\hline C14:0 & $0.40 \pm 0.02$ & $0.39 \pm 0.01$ & $0.39 \pm 0.03$ & $0.38 \pm 0.03$ & $0.35 \pm 0.03$ \\
\hline C16:0 & $28.41 \pm 0.18$ & $27.54 \pm 0.79$ & $26.62 \pm 0.25$ & $24.82 \pm 1.14$ & $25.05 \pm 0.28$ \\
\hline C18:0 & $2.12 \pm 0.75$ & $2.58 \pm 0.18$ & $1.95 \pm 0.54$ & $2.63 \pm 0.06$ & $2.48 \pm 1.07$ \\
\hline C20:0 & $0.34 \pm 0.05$ & $0.26 \pm 0.01$ & $0.28 \pm 0.06$ & $0.34 \pm 0.05$ & $0.34 \pm 0.04$ \\
\hline C24:0 & $0.18 \pm 0.02$ & $0.16 \pm 0.02$ & $0.14 \pm 0.04$ & $0.18 \pm 0.03$ & $0.13 \pm 0.02$ \\
\hline C16:1 & $5.50 \pm 0.50$ & $6.10 \pm 0.25$ & $6.01 \pm 0.38$ & $5.94 \pm 0.28$ & $6.10 \pm 0.45$ \\
\hline C18:1 & $49.78 \pm 1.09$ & $52.19 \pm 1.00$ & $53.63 \pm 0.30$ & $53.21 \pm 2.18$ & $53.34 \pm 1.28$ \\
\hline C22:1 & $0.18 \pm 0.04$ & $0.14 \pm 0.01$ & $0.14 \pm 0.02$ & $0.18 \pm 0.04$ & $0.16 \pm 0.02$ \\
\hline C18:2 & $12.88 \pm 1.98$ & $10.41 \pm 0.08$ & $10.62 \pm 1.03$ & $12.12 \pm 1.24$ & $11.83 \pm 1.28$ \\
\hline C18:3 & $0.21 \pm 0.05$ & $0.24 \pm 0.05$ & $0.22 \pm 0.00$ & $0.20 \pm 0.04$ & $0.22 \pm 0.01$ \\
\hline SFA & $31.45 \pm 0.71$ & $30.93 \pm 0.96$ & $29.38 \pm 0.68$ & $28.35 \pm 1.20$ & $28.35 \pm 1.22$ \\
\hline MUFA & $55.46 \pm 1.50$ & $58.42 \pm 0.96$ & $59.78 \pm 0.59$ & $59.33 \pm 2.42$ & $59.60 \pm 1.47$ \\
\hline \multirow[t]{2}{*}{ PUFA } & $13.09 \pm 1.92$ & $10.65 \pm 0.12$ & $10.84 \pm 1.03$ & $12.32 \pm 1.27$ & $12.05 \pm 1.28$ \\
\hline & 100.00 & 100.00 & 100.00 & 100.00 & 100.00 \\
\hline
\end{tabular}

SFA: saturated fatty acids; MUFA: monounsaturated fatty acids; PUFA: polyunsaturated fatty acids

Table S7. Serum leptin levels in mice

\begin{tabular}{ccccc}
\hline & Palm olein & P90 & P50 & Olive oil \\
\hline Leptin Level $(\mu \mathrm{g} / \mathbf{d L})$ & $8.49 \pm 0.53^{\mathrm{a}}$ & $10.41 \pm 0.74^{\mathrm{b}}$ & $9.94 \pm 0.84^{\mathrm{a}, \mathrm{b}, \mathrm{c}}$ & $11.30 \pm 0.52^{\mathrm{b}, \mathrm{c}, \mathrm{d}}$ \\
\hline
\end{tabular}

Different letters denote $p<0.05$.

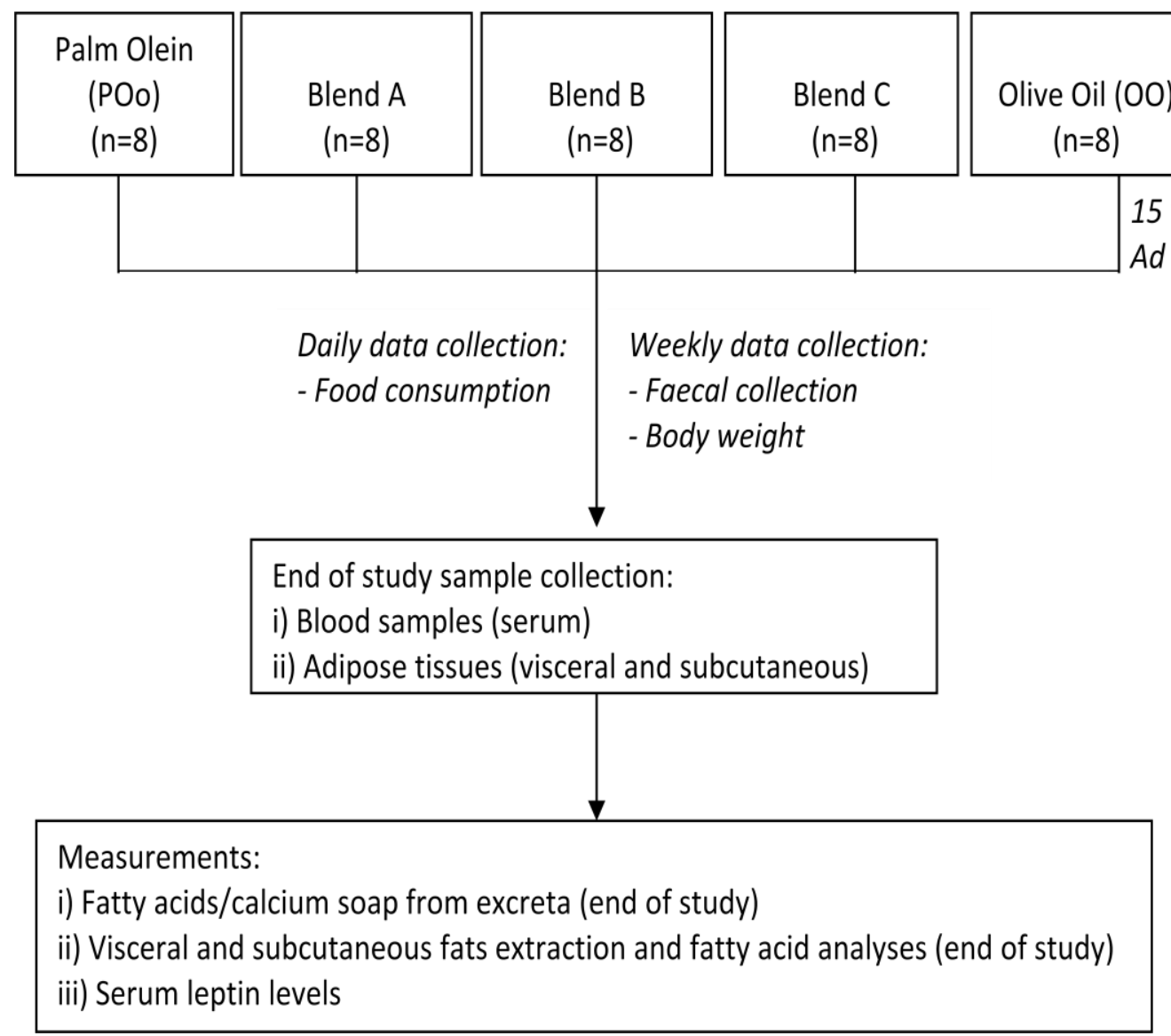

Figure S1. Flow of study 
<smiles></smiles> 